\title{
Prescribing, care and resistance: antibiotic use in urban South Africa
}

Lenore Manderson (10 ${ }^{1 凶}$

In South Africa, patients' and providers' expectations of transactions in health services converge in consultations for acute respiratory tract infections with the prescription of antibiotics. To explore this, a qualitative study was undertaken at community health centres and private general practice surgeries in four areas of metropolitan South Africa, selected purposively to allow for wide variability in terms of socioeconomic status and ethnicities/race of patient populations. With permission, clinic waiting rooms and patient/provider consultations were observed, and 65 in-depth interviews were undertaken with patients or parents or guardians presenting with children. These interviews were complemented by interviews with health providers (26) and key informants (12). All interviews were recorded, transcribed and imported into NVivo 12 for management. Data were open coded, with individual interviews and observational data compared and contrasted to highlight understandings and practices of care, antibiotic precription and use. In this article, I illustrate how the social context of patient and provider interactions in primary care settings influenced treatment. Community health centres and clinics were (and are) stretched for resources, and there were long wait times before patients can be seen; consultations were brief, with relatively little verbal exchange on the management of coughs and colds. Providers' decisions of treatment were informed by clinical assessment, concern about the risks of bacterial infection, and perceptions of patient ability to seek further care and advice-a mix of clinical and social considerations. While patients did not always request antibiotics and were willing to discuss how to manage acute conditions without them, doctors in private practice still often provided a prescription, sometimes post-dated to discourage use but with the option for medication if needed. In the public sector, the provision of a prescription also reflected clinicans' appreciation of economic constraint and vulnerability. As described, patients understood principles of the appropriate use and storage of antibiotics, in contrast to other medications, and they were largely open to discussions with their providers about whether or not to use an antibiotic. However, their own and their prescribing providers had varied understandings of the mechanisms of resistance to antibiotics and so the need for antibiotic stewardship.

\footnotetext{
${ }^{1}$ School of Public Health, University of the Witwatersrand, Johannesburg, South Africa. ${ }^{\bowtie}$ email: lenore.manderson@wits.ac.za
} 


\section{Introduction}

ver the past three decades, antimicrobial and particularly antibiotic resistance has accelerated worldwide, and with it, growing advocacy for the global coordination of surveillance and attention to its public health impacts (Critchley Karlowsky, 2004; Smith Coast, 2002). The Global Action Plan and a global surveillance system were not initiated by the WHO until 2014 and adopted in 2015 (Shallcross \& Davies, 2014; WHO, 2015), ${ }^{1}$ and by this time, antibiotic resistance was widely recognised as a major threat to Sustainable Development Goals associated with health and wellbeing, food security, employment, and the reduction of poverty and inequality. In the context of this concern, there has been growing attention to how social and structural factors contribute to resistance, so to develop effective interventions to prevent a public health catastrophe. As a number of authors have noted (e.g. Greenhough et al., 2018; Hinchliffe et al., 2018), this has concentrated on sanitation and the prophylatic and therapeutic overuse of antibiotics in hospital and community settings.

In this domain, the published literature has largely concentrated on the global north, despite acknowledgement that this is both a global problem and a problem of globalisation. The expanding literature draws attention to the complicated mix of circumstances shaping overuse. European studies (Machowska \& Lundborg, 2019), for example, have highlighted patients' (mis) use of antibiotics in relation to access to antibiotics without prescription and to using leftover antibiotics, but also pointed to provider variables and patient-doctor interactions as influencing the unwarranted use of the drugs. Here and in other studies in Europe (Akkerman et al., 2005; Cabral et al., 2019; Lucas et al., 2015; Tonkin-Crine et al., 2011) and Australia (Dallas et al., 2015; Fletcher-Lartey et al., 2016; Lum et al., 2018), prescribing practice is often linked to providers' perceptions that patients expect drugs, although this is not necessarily the case. Independent of patient expectations, providers with limited experience in treating respiratory infections are more likely to inappropriately prescribe antibiotics. In their review, Rose et al. (2019) note that diagnostic uncertainty and risk management, and lack of time to spend with individual patients, both influence prescribing behaviour. In addition, Kumar et al. (2003) have shown that doctors in the UK are more likely to prescribe antibiotics to patients of low socioeconomic background.

We know less of the drivers of antibiotic use and resistance in human patient populations in low- and middle-income countries, despite claims that the inappropriate use of antibiotics is a serious problem in such settings (Godman et al., 2019; Greer et al., 2018) and despite researchers' emphasis on different variables across national and local settings. Available studies illustrate that in addition to the poor regulation and ready availability without prescription of antibiotics in many low-income settings, multiple factors at the primary care level influence the provision of antibiotics (Ayukekbong et al., 2017; Le Doare et al., 2015). In China, for example, Liu et al. (2019a) argue that lack of education about antibiotic misuse and resistance among health providers and patients, and patient pressure for medication, are both relevant, but also that there is higher antibiotic use in rural and lowsocioeconomic settings. Multiple factors overlap and intersect to contribute to the increasingly dangerous use of antibiotics: provider uncertainty of cause of illness and outcome; concern for patient health and awareness of the constraints in which they live; patient expectations for medication; patient poverty and actions to ensure their own and their families' health; health systems failures; limited training and lack of continuing education for providers; inconsistence advice to patients; and the regulation and surveillance of drug supply. These factors all influence what drugs are available, how they are accessed, and how they are used.
Despite acknowledging this context, actions to address antibiotic resistance have centred on educational efforts to reduce the incidence of inappropriate prescribing and use of medication in hospital settings, in industry, including agricultural production, and in the community. To address assumed knowledge deficits at a community-level, programmes have been developed to deliver generic informational messages (Andersen et al., 2019; CatalanMatamoros et al., 2019; Davis et al., 2018). Various authors (Charoenboon et al., 2019; Haenssgen, 2019; Haenssgen et al., 2018) have drawn attention to the limits to this approach, including the risk that community members might misunderstand messages, and the failure of these approaches to address the context that drives antibiotic demand and use. They emphasise that precarity, rather than "alleged knowledge deficit", is key to the suboptimal use of antibiotics and other antimicrobials (e.g., for tuberculosis, malaria and HIV). Others too have highlighted the social determinants of heath, including individual and household level poverty, and systems challenges affecting infrastructure, health services and accessibility of care (Alividza et al., 2018). Willis and Chandler (2019) have framed antibiotic prescribing as a "quick fix" to address proximal medical problems associated with social structural conditions, so bypassing the challenges of these wider problems. In this article, I turn to South Africa to tease out some of the factors in the provision of health care, health systems and structural factors, and communication between providers and patients that influence the use of antibiotics.

\section{Background}

Without local information on which basis to respond to emerging antimicrobial resistance, low- and middle-income country governments and professional networks have largely drawn on measures adopted in high-income settings, particularly the UK and the USA (Chandler, 2019; Podolsky, 2018). However, increasingly, with interest in the social context of health care, antimicrobial resistance and its unfolding, scholars have emphasised the importance of research in poorer income countries where self-medication and over-prescription of antibiotics are widespread (Ayukekbong et al., 2017; Fendrick et al., 2001; Founou et al., 2017; Torres et al., 2019; Van Boeckel et al., 2014; Wernli et al., 2017).

South Africa is an upper middle-income country, one of the wealthiest on the continent, with a gross national income per capita of $\$ 13,250$ (PPP). It is also the most unequal country, with a Gini coefficient estimated by the World Bank of 0.63 in 2015, virtually unchanged since the end of apartheid (1994) and reflecting apartheid's continued legacy. This legacy manifests in deeply unequal access to health care, quality of care, housing, water and sanitation, employment and poverty (Gordon et al., 2020). The escalating burden of antibiotic resistance is one additional burden to this mix. For well over a decade, medical professionals, including microbiologists, doctors and pharmacists, and government actors at a ministerial level and within the national Ministry of Health, have been concerned with antimicrobial resistance, including resistance to antibiotics (Essack et al., 2019, 2018, 2017).

Antimicrobial stewardship-measures to prevent the misuse and overuse of drugs to deter resistance-came into professional focus in South Africa with the establishment of the Federation of Infectious Diseases Societies of Southern Africa (FIDSSA) in 2005 (Brink, 2008), then with the South African Antibiotic Stewardship Programme (SAASP) in 2011. In 2014, a multidisciplinary and intersectoral Ministerial Advisory Committee (MAC) was established to inform a national AMR strategy framework (Mendelson 
and Matsoso, 2015); it continues to meet. In the framework documentation, reduced levels of resistance and antibiotic stewardship were linked to the need to strengthen the involvement of pharmacists to support appropriate medication in hospitals, and in communities, the need to increase the uptake of influenza and pneumonia vaccinations for people at high risk (for example, people with HIV and/or TB). There was expressed concern with the overuse of both veterinary and human medicines for food animals and companion animals, thus veterinarians were included on the MAC, contributing to a nascent and growing interest in a One Health approach globally (Ekwanzala et al., 2018; Essack, 2018; Mendelson et al., 2018; van den Honert et al., 2018). The framework in addition emphasised the need for infrastructural improvements to ensure water safety and optimum conditions for hygiene and sanitation. Given problems with governance and pervasive inequality (World Bank, 2018), this is a continued challenge.

Along with concern about vaccination coverage and hygiene and sanitation measures in community settings, there has been consistent concern about community-level antibiotic resistance, reflecting patient demand for and inappropriate prescriptions of antibiotics in primary care setting for upper respiratory tract and other common infections (Brink et al., 2016; Essack et al., 2019; Truter \& Knoesen, 2018; Watkins et al., 2019). Below, I focus on the provision and use of antibiotic drugs as understood by adult patients, adults presenting with children, and health providers, including both general practitioners and nurse practitioners. Drawing on in-depth interviews and observations in urban primary care settings, the study findings highlight the variability in perceptions and practices concerning antibiotics, including that antibiotic prescriptions may not be necessary. Both patients and practitioners illustrate how structural factors work against quality of care. The challenge in the custodianship of antibiotics cannot be met only by educating doctors, nurses, community pharmacists and patients, but also by addressing the conditions under which people live, and receive care and advice.

\section{Methods}

In this article, I draw on qualitative data collected at eight clinics -one private medical centre and one government health facility in each of four socioeconomically diverse wards in metropolitan South Africa. These facilities were located 9-19 km from the inner city of a major South African city on an arc from north east to west and south, so allowing the inclusion of middle class and very wealthy areas of residence, delapidated old apartment blocks, and rudimentary shacks located in informal settlements. Purposive sampling of these areas ensured we were able to compare and contrast private doctor's surgeries with community health centres, as were made available to people from different race backgrounds, with white patients most likely to attend private surgeries, Indian patients both private and public, and Coloured and black African patients largely presenting for care at community health centres. The study was conducted from June-September 2017, winter months in the southern hemisphere when colds and flu are typically prevalent.

The study constituted Phase I of a three phase study designed to examine general practitioner prescribing practices, with Phase II and III, respectively, a survey and a study of doctors' responses to patients presenting with upper respiratory tract infection (not reported here). In Phase I, permission was sought from the municipality, facility staff and patients to conduct observations in waiting rooms; permission was sought directly from the patient (or parent or guardian when the patient was a child) and health providers for observations of doctor-patient and nurse practitioner-patient consultations in the case of reported colds and flu. During observations, researcher assistants took extended notes and attended to communication, examination, the provision (or not) of prescriptions, and advice. Adult patients and parents or guardians bringing small children to a clinic (almost all mothers or grandmothers) were approached for individual interviews. All patients who agreed to interviews were female (presenting for own illness, or as the mother or grandmother of a child), hereafter, depending on context, referred to variously as participants, patients or women, as only women were interviewed. Participants were aged 20-70, the majority of mothers 20-39 and grandmothers 40; all women in the poorest areas were from the majority black African and Coloured populations, while most women attending private surgeries were white or Indian. Women were often interviewed while waiting to be seen by a doctor or nurse practitioner, or following consultation if they were not eager to return home, always in a quiet area of the clinic where privacy could be assured. In some cases arrangements were made for interviews at home at a later date, in which case a contact number was provided by the patient. In total, on consent, 65 semi-structured interviews were conducted by two trained research assistants in English following an interview guide. In addition, health providers were interviewed: 8 doctors (equal numbers of Indian men and white women, estimated ages 40-65); 15 nurse practioners and senior community nurses (the majority black African women); and 2 pharmacists (1 Indian; 1 coloured). An observational guide was used for clinic observations, which generally lasted for around $4-5 \mathrm{~h}$ and were randomised so that observations were conducted in each clinic at different times (morning/afternoon) and days of week for all clinics. Open-ended interviews with key informants $(n=12)$ were conducted by the author with advocates of antibiotic guardianship, including senior clinicians and research scientists, government programme officers and pharmacists, again with an interview guide; these people were recruited through snowballing and referral. All interviews were audio-recorded; transcribed into Word by a professional transcriber; then checked and imported into NVivo 12 (QSR International, 2019).

Analysis involved reading and rereading transcriptions and observational notes to gain an overview and sense of dominant themes. Data were then coded, with each line numbered in the transcript and meaning units marked up, and were regularly revised to allow for subcodes and subtle differences in meaning. Codes in individual transcripts were then categorised into emergent themes, including to identify recurrent codes, patterns and clusters of text. Final themes were elaborated with memos and linked with similar themes, and contradictory and discordant themes were identified within and across accounts. Observational data and interviews highlighted diverse understandings, expectations and provisions of care, prescribing practices, communication between clinicians and patients, and contradictory understandings of antibiotic resistance. Ethics approval was provided by the Human Research Ethics Committee (Medical) of the University of the Witwatersrand, Johannesburg (M1611120).

Patients' understandings and home management. Patients drew on their own experiences with regard to the timing, prevalence and modes of transmission of colds and influenza. Consistent with time of the study when colds and flus are most prevalent, participants associated signs of infection, such as sneezing, nasal congestion, sore throat and cough, with winter time and cold weather. Women linked infection with exposure, including playing in cold weather and with cold water, and bathing in cold water. Interviewees also noted children's exposure to others in creches, childcare centres and at schools, and the role of this in transmission, such that participants were clear about pathways of 
infection: "One child gets the flu then the other one will get it straight away, and then it comes to me"; "Sometimes there's infection from within the family. You know, it can be one person who has got that and then at the end of the day, it ends up (infecting) the whole family".

Given the emphasis that women placed on coldness as contributing to the risk of infection, they considered being warm to be preventive, and so stressed in interviews the importance of ensuring that children were warmly dressed, especially when outdoors in the evening, and that they did not play in the rain. Women reflected on children's vulnerability, likely because of where and when they were recruited into the study (that is, while seeking medical advice for children with colds). However, their understanding of the risks and spread of infection was applied to adults as well. One woman, drawing on her husband's experience of working in a restaurant, explained how work conditions and limited adherence to hygiene combined to predispose a person to infection:

Sometimes you wake up very early and it is very cold ... and when you get to work, there are no heaters or anything and you still need to stand up on the cold floor and then your feet get cold and stiff. And the other reason is maybe we don't wash our hands like regularly, so for like the whole day you eat like everything that you come across, you just chow (eat): like you go to the toilet and maybe you don't wash your hands. When you come back you forget that you are still working with different customers ... and they have got those infections already. Then you are sitting in those places, and in the kitchen maybe there are leftovers and you still chow those leftovers. That is the other cause that makes us get flu especially in winter.

In this account, the emphasis is again on ambient temperature (and so feeling cold) and exposure to others with infection, although also on hygiene. Crowded conditions were widely seen to exacerbate the risk of infection, both in public places where people were in close contact, in taxi minibuses, for instance, and at home. In winter, one woman noted, "people are more indoors, so more likely to be closer to other people. So, more contact in smaller indoor places, so it gets spread more. It's spread from one person to the next". Thus, women's experiential knowledge of the contexts and risks of transmission align with biomedical understandings. Women regarded flu and colds as a "disease for everyone", which could be managed at home and did not usually interfere with everyday activities.

Consistent with this, home treatment involved warmthwarm baths, a warm bed, and warm drinks, such as drinks with lemon and honey. Inexpensive over-the-counter medication was also used for self-medication for symptomatic relief: Panado (paracetamol) and Grandpa (a powder combining aspirin, paracetamol and caffeine) to relieve headaches, sore throats and fever; Vicks VapoRub and other salves, expectorants and inhalants that typically included menthol, camphor and eucalyptus oil. Any of these proprietary products might relieve a blocked nose, coughing and sore throat, and were available, depending on weight/volume and numbers of tablets, for less than 20 Rand (<US\$1.50) in supermarkets, chain stores, and franchised pharmacies. Products such as Grandpa could also be purchased from small local convenience shops (spaza); they were, therefore, readily available to householders wherever they lived. In addition, interviewees whose child or who themselves had a history of asthma often mentioned using a bronchodilator; some of these were also available without prescription, as were particular medications available as syrups rather than inhalants for people with chronic lung disease.
Advice from the clinic. Give that coughs, colds and flu in winter were considered mundane and manageable, patients saw no need to seek advice from a pharmacist, or clinic nurse or medical doctor (general practitioner) unless signs and symptoms persisted and/or were considered severe, interfering with everyday activities such as going to work or the capacity to undertake household tasks including the care of others. Likewise, mothers, grandmothers or guardians accompanied others to seek advice only if symptoms were considered severe. At this point, some women reported that they might seek over-the-counter advice and purchase over-the-counter medication, as above, and might ask for an antibiotic if they had prior experience of taking such medication for a cold or flu.

With debilitating or persistent symptoms, women eventually presented to a private or public clinic for advice (where we met them). Choice of clinic depended on income and whether or not they had private health insurance, the latter factor determining the quality of care in the private sector that was available to employed middle class patients, compared with resort to the public sector by the majority of the population, most on a low income or unemployed (Ataguba \& Goudge, 2012; Fusheini et al., 2018; Girdwood et al., 2019). Those without health insurance or sufficient money to pay out-of-pocket presented to a community health clinic or hospital outpatient department, often leaving home early in the morning to be in a queue by eight am with hope of being seen by midday (see, for example, Sastry et al., 2015). Women reported borrowing from others to cover the indirect costs of clinic attendance, such as transport and possible charges for medication. Women without the cash to pay for a taxi minibus or bus might walk for half an hour to an hour, although because the study was in an urban setting, no women lived further than this from a public clinic.

Women usually delayed presenting to the clinic not only because of home management, but because of protracted clinic waiting times and bottle necks (Egbujie et al., 2018; Sastry et al., 2015; Stime et al., 2018; Swart et al., 2018). As many women explained, it seemed pointless to present to the clinic and wait for some hours, with no resolution at the end of the day: "You'd rather try helping yourself at home, rather than coming to the clinic". Once at the clinic, however, most people accepted pragmatically that they might need to wait for 3 to $4 \mathrm{~h}$. Only one participant expressed particular frustration with quality of care, in which she included poor triage, slowness in retrieving patient files, long queues to see a practitioner, limited time spent in consultation, lack of medication available at the clinic (seen by her as due to the failure of clinic staff to stock take), and poor management of staff time, including times for breaks. To reduce wait time and to ensure satisfactory visits, poorer women (recruited from community health clinics) also made strategic decisions about which clinic to attend. Hence they did not always attending the clinic nearest to their home, but chose between clinics or between a clinic and hospital. One patient explained this in relation both to access to medicine and to expanations and advice:

The service here is much better, because the other places you may find most of the time they don't have medication ... with the other ones you sit a long time, then at the end there is no medication ... I expect my service, I expect that by the time I leave here, I would have had answers, because I don't just sit in a doctor's room and say "it's painful here, it's painful there", then I am given the medication and that's it. I want to know why. And at times you know, other doctors, they are not free people to talk to you.

Prescribing nurses and doctors in public clinics described that their decision-making for treatment was based on symptoms, and 
they talked about the advice they gave to patients, including whether or not they had prescribed antibiotics, timing and frequency of taking medication, the importance of finishing any prescribed medication, and storage. Often this included a small statement about the risk of resistance, as one nurse explained: "They must finish the course. They shouldn't just drink (take) them for two days. Once they start feeling better, maybe they stop. They must finish the course in order to prevent also, what's this thing? Resistance. Developing resistance". Providers reinforced the need to educate their patients and to address their queries, although they felt they were one voice of many:

They know the side effects, they say "have google". They tell me. They tell you, so you need to be open minded. Talk to them. And then even if you do end up giving them antibiotics, tell them that you're actually prey to resistance. (And tell them) you are destroying your immune system... and then next time when they start considering these things ... education is the only way actually.

Much health education and the advice given by providers to patients was pragmatic: adhering to timing and completing the course; not sharing prescribed medicine with others; not using anybody else's medicine. They emphasised the need to keep syrup in the fridge, or if there was no fridge, in a cool place out of reach of children. In interviews, women tended to repeat these injunctions: "Um, in a cupboard, faraway from the kids! (laughs) Even if it's low, I must lock it". Not all adhered to advice, however. A few women explained that they kept drugs "oh, anywhere! On top of the table or anywhere. But not in the fridge, I don't put them in the fridge, I don't like things that are kept in the fridge. Sometimes ja, ja, I do hide them on top of the wardrobe, but he (child) normally takes a chair and climbs and takes everything down".

Patients were also advised to keep medication in the original packaging or separate containers to avoid confusion about different times to take medication and possible contamination. One provider elaborated: "Some antibiotics don't want you mixing them. You know, you get those very old ladies? They will take all their medication and throw them into one container. Some pills don't want it like that, so you need to talk about these type of things".

In the end, the primary purpose of such advice was to ensure adherence to antibiotic use through what providers characterised as "fear" or "obligation". Particularly in the public sector, providers emphasised that they had no time to do more than remind their patients about complying with the prescription; in our study, doctors and nurse practitioners spent around $5 \mathrm{~min}$ only with each patient. They emphasised that their colleagues were likewise constrained and so necessarily focused on the minimum information: "The workload is kind of too much for us ... that's why I think sometimes, probably it's just to cover yourself (by prescribing antibiotics), or sometimes because there's little time to give a health education". In practice, therefore, advice from providers to patients was usually limited simply to reiterating the need to take medication as prescribed, $8 \mathrm{~h}$ a day if three times a day, for instance, before or after meals, and so on, and to keep medication in a cool and safe place away from children. They did not expand on treatment, self care or antibiotic resistance, and given that they spent limited time with any patient, they arguably had no time to do so.

Further, while in interviews providers claimed that patients asked for antibiotics, at all observations we undertook, patients spoke only when spoken to, said very little, and did not initiate conversation, ask questions, request an antibiotic, nor challenge a providers' failure to prescribe one. Thus, notwithstanding the possibility of observation effects on interactions, doctor and nurse prescriber claims that "the first thing that they (patients) ask for is antibiotics ... most of them demand (them)" are generalised perceptions not confirmed by observations.

Providers insisted that patients associated clinical consultations with the prescription of medicine: "You know some of them (patients) have that perception! It's a misconception but they do have the perception that if they leave here and you haven't given them an antibiotic then they have wasted their money on their consultation - that you haven't done enough for them". This was contradicted by their view too that some patients, including poorer patients in public clinics, had "good knowledge" of antibiotic resistance and would question the rationale for prescribing or withholding medication, or would be responsive to advice to "wait and see:" "People today go googling things. At times they'll be telling you, "Sister, don't you think I must get an antibiotic?" We will explain that this is viral. You don't need an antibiotic. You just need rest, fluids, take your Panado. Your cough mixture".

Women at private clinics were likely established clients and, in contrast to those at public clinics, they often knew the practitioner and other staff at the surgery. They expected to be seen relatively promptly and to have time to discuss their health problems. General practitioners in private practice, however, felt that consultation times were still short and this limited their ability to examine a patient and offer advice about reducing or resolving symptoms: they were "under pressure with regards to the amount of time we are able to spend educating our patients". Even so, relatively longer consultation times in private clinics, including discretionary time when the waiting room was not crowded, allowed doctors to discuss other ways of managing respiratory infection and the option of a post-dated prescription. Health care professionals felt responsible to ensure that their patients understood the logic behind prescribing an antibiotic, or not doing so; they emphasised the importance of patient education and strategies to limit the use of antibiotics:

It is probably their education and their understanding of what it is, where they have certain expectations to be given the antibiotic. And they actually really feel like they don't get better until they have the antibiotic. ... What I tend to do is that I often give them two scripts (prescriptions): where I will give them a script (for symptom relief) and say "take this medication, give it about three or four days, and if you see you are not getting better, we can get the antibiotic". So a lot of them feel a lot more better knowing that they have the option to take the antibiotic should they not be getting better, and nine out of ten times they actually don't get the antibiotic.

The social context of prescribing. As noted above, patients sought medical advice concerning continuing symptoms of upper respiratory tract infections, particularly when these impacted on everyday life-on turning up for work, caring for children or others, undertaking household tasks. Women especially may juggle all of these with the debilitating effects of a severe head cold. Presentation to a clinic may require no more than reassurance that the condition is self-limiting and confirmation that the patient's approach to mitigate symptoms is appropriate. Most patients stated that they did not necessarily expect to be prescribed an antibiotic: "Ai, when he didn't give me (a prescription), I said okay it's fine, because you can't force them to give me the medicine". Others were clear that they did expect a prescription and explained that they had gone to they clinic for this purpose: "I will say I wasted my time to come to the clinic, because I was expecting antibiotics from them". 
Providers emphasised that they did not prescribe antibiotics at point of care, unless clearly indicated, although as described above, some mentioned post-dated prescriptions. Providers spoke of the tension between patient expectations and their stewardship roles: "I base my decision purely medically and clinically. And I am a prescribing doctor, not a dispensing doctor". Providers used time with patients to talk through this decision-making, as one doctor in private practice explained: "My patients have learnt over the years that they are not just going to get an antibiotic. So they readily accept it. And they also know that if they do call, there is going to be a response to that call; it is not going to be ignored". In this case, patients were given a phone number and asked to telephone if there were a change in their own condition or that of a child, without having to return to the clinic. This was also the ideal of health providers working in government clinics:

So every time I give an antibiotic or don't give an antibiotic, I explain why I'm doing it, so that I encourage the patients to have that, are armed with that knowledge. Then the expectations wouldn't be there... (and) ideally, they wouldn't want the antibiotics unless necessary ... You have to make sure that they understand why they are getting it or why they are not getting it. You have to make sure they understand how to take it.

Notwithstanding this, doctors and nurse providers felt some responsibility to offer patients more than advice: "You are just put in a tight corner. You have to give something".

Providers in both public and private clinics also explained that at times they prescribed an antibiotic for an upper respiratory tract infection based on what they perceived to be the risks of acquiring a bacterial infection or the possibility that the infection was bacterial not viral. These factors came together with understandings of local contingencies and taken-for-granted conditions. That is, health providers drew on their understanding of risk factors for infection as mediated or exacerbated by social and economic circumstances. This included their consideration of monetary constraints that would prevent a patient's ability to pay for pathology tests to establish if the infection were bacterial or viral. They also considered the time involved and the willingness, feasibility and costs for a patient to return for a second consultation were there no improvement: these factors might include taking time off work (without pay) to keep a clinic appointment, and the cost of transport and perhaps childcare.

In these contexts, doctors worked through a range of symptoms and medical history to clarify the need, or not, of an antibiotic. Patients were more likely to be prescribed an oral antibiotic, for example, in the case of fever, tonsillitis "because of the strep and the rheumatic heart disease links", otitis media, a history of asthma, persistent infection following treatment, or suspected pneumonia. Specific variations in symptoms might also be considered to signal bacterial infection:

What do you look out for that makes you decide "okay, I need to give this one an antibiotic, and this one would not need an antibiotic?" So ENT complaints that are caused by bacterial pathogens, so for example your sinusitis, where patients have high temperatures, where they have the foul smell, where they have lost sense of taste, sense of smell, where they are having a foul-smelling discharge. And when they have the facial sinus tenderness ... the fact that they had the spiking temperatures, and persistent headaches, would make me say "this is not just a sinus congestion or inflammation, but an infection". With the ears ... when you see a bright red with an inflamed tympanic membrane, they need an antibiotic. Tonsils, enlarged tonsils - a lot of the time we see with pustules or funicular tonsillitis. And those are the ones that we give antibiotics.

Providers therefore illustrated how they differentiated clinically between viral and bacterial infection, which included the colour of phlegm, fever, white patches on the throat, swollen or tender glands in the neck area. They did not consider that they overprescribed, but they did describe other providers as doing so: "Instead of giving a cough mixture, they will add an antibiotic. That one, hey, it's happening everywhere ... it's a problem everywhere", and "I don't believe there is any difference really between the private and public sector; it's amazing how doctors just willy nilly prescribe antibiotics".

These clinical signs and symptoms were supplemented by social considerations, so that providers developed personal algorithms to determine the need for antibiotic presecriptions. Providers explained, for example, that antibiotics were often indicated because of delays in presenting for care and so the severity of illness at time of consultation. Antibiotics were also prescribed in the context of the challenges of a public clinic, which impacted on patients and providers: "It's more difficult to access clinics. Waiting times are longer. Resources are more limited for the patients as well as the facilities. So there, yes, you would be on occasion be tempted to treat with antibiotics". At times, their own accounts of consultations mirrored observations:

Like I'm saying, you can't blame the doctor. You see the workload. Like I'm saying, most of the time, you'll find this patient is trying to explain something, but he was not given enough time, and the doctor also. There's a queue there.... the patient will come and say I've got flu and then you (doctor) will ask him is it tonsils? And he will just say yes, and then you will write the prescription. You know? Because you don't have time.

Public and private health services generally map onto patient economic status, and for this reason, contextual factors were also always included in provider accounts of prescribing practice. In particular, practitioners who worked in areas of the most marked socioeconomic disparities described how social and economic factors contributed to poor health and interfered with treatment seeking:

The economic situation that they go through or they have, the burden of disease is high, it's very high in this community, they always come sick and three out of five patients that you see have a chance to have an infection, be it an ear infection, throat infection, abdominal infection, gastroenteritis, whatever it is, they always have it.

The personal circumstances of patients also influenced provider perceptions of risk and so their prescribing patterns. One provider emphasised that she always asked where a patient lived: "You will ask about the address. She's staying in the shacks and also she complains about maybe greenish or yellowish sputum. I see that they won't come back ... (so) then I cover them with an antibiotic". In elaborating on this, providers emphasised in interviews the difficulties faced by patients who did not have a fixed income, could not take time off work, or lived on a government grant, were a sole parent, or had multiple responsibilities for other people. As one provider reflected, prescribing was influenced by the perception that it would "be a strain on the patient's finances to have to come back". If they felt that a patient lacked the ability to pay for additional consultations, then they might rethink the need for a prescription and the advice offered. One nurse practitioner summarised this bluntly: "You just look at the condition and (think): this one is leading a fast life or this one doesn't even have a place to stay". 
In general, if a patient had travelled a long distance to a clinic and lived in a poor area, and there were obvious or assumed difficulties for them to return, then they would most likely receive an antibiotic prescription. If the patient was a local resident, then access was less an issue; instead, the provider might encourage reappraisal, advising a parent to wait and see: "Look, give it two days, if she (patient) is not better after two days, bring her in. We are not going to charge you a consultation fee, we will see you then". Providers often also contrasted working in a metropolitan setting with a rural setting: "If I were in rural medicine", one provider explained, "for you to come back to me, it is going to take $4 \mathrm{~h}$ walking and it is a lot of money, you don't have the money, you have only got one person who can bring a child to the clinic, then I would probably give them an antibiotic".

These considerations were often compounded by providers' belief that usually, patients presented to clinics having exhausted all other avenues, including symptomatic relief through over-thecounter products. Legal concerns were also mentioned, but rarely:

I think prescribing is also a protective thing, a medical legal protective thing, that I gave the antibiotic. They were still sick but I gave them everything I could give them. You kind of protect yourself, where if you don't give the antibiotic and they are sick or something else complicated, how do you justify not giving the antibiotic, you know what I mean?

\section{Understandings of resistance.}

Wow. I can't even remember the last time I spoke about that. Resistance? What do you want to know about resistance? Why do you think resistance is happening with antibiotics these days? Are you aware of it? Ja, the people are abusing them. People are abusing, um, antibiotics. Like I said, the more you use them, the chances of creating resistance increases (general practitioner).

Towards the end of interviews, unless they had introduced the topic earlier, patients and providers were asked about antibiotic resistance, and what they understood this to mean.

Concern about the inappropriate use of antibiotics influenced general practitioners' and nurse practitioners' understandings of when and why antibiotics might be prescribed, and the emphasis they placed on antibiotic safe keeping and compliance with prescriptions. These core components of everyday stewardshiplooking after medicines and using them properly-are common to other drugs prescribed for prevalent chronic conditions, including medication for cardiometabolic conditions (heart and diabetes), antiretroviral treatment for HIV, and tuberculosis. Other pharmaceuticals are taken regularly for prevention not treatment-contraceptives, for instance, or are given at specific times only, as for vaccinations.

Arguably most adult South Africans have some understanding of the appropriate use of drugs from personal experience and health education. Advice to patients to take medicine "as directed" and keep it "in a safe place" is routine, as illustrated above. It is easy to transfer this message to the care and use of antibiotics, although patient practice varied regarding where and how they stored medicines, again as above, and how they disposed of unused medicine. However, preventive medicine and the management of signs (of hypertension, hyperlipidemia or asthma, for instance) do not provide an analogy for preventing bacterial infection with an antibiotic. Rather, the message of stewardship directed to doctors, and from doctors to patients, is contradictory: patients should observe how the condition or sets of symptoms unfold; doctors should consider symptoms as self- limiting until proven otherwise, and prescribe only if absolutely necessary. Thus in a clinical encounter, providers have to deliver a different message than they might otherwise do.

Providers and patients were inconsistent and equivocal in how they understood resistance, despite that resistance is at the core of contemporary concerns about antibiotic effectiveness. Participants often used the term resistance in reference to immunity, ineffectiveness of a drug, and occasionally allergy. A patient might develop "resistance" to penicillin (that is, a negative reaction) and require an alternative medication; they might develop resistance to a particular drug, because it is ineffective for them even if effective for others with the same condition. Alternately, the bacteria might be considered resistant to the medication because the choice of drug was incorrect. While some providers mentioned that bacteria develop resistance genetically to a drug, associated with the inappropriate use of antibiotics, more often providers as well as patients saw this to be a problem at a patient level. The patient and their embodied symptoms of infection were being treated; with resistance, as they understood it, there was a risk in the future that the same symptoms might not respond to treatment or, alternatively, that the prescribed antibiotic would no longer be effective for them. As one doctor explained, "a person can become resistant". A nurse provider similarly explained that she discouraged antibiotic prescriptions for patients who were "actually prey to resistance. You are destroying your immune system". In this understanding, resistance was when a drug didn't work because the patient had became resistant. Usually, it was explained, this was because they had not completed a course as prescribed.

To avoid this, as noted above, education to patients at the time of consultation, at both community health clinics and private surgeries, centred on adherence, as one patient described: "I have to use it according to the way they tell me how to use it. So if they tell you to use it three times a day and take it before food or after food, and you use it like that, it is going to work. Yes. It must work because I'm following the orders. The doctor's orders". Likewise, a pharmacist emphasised to patients the importance of completing a course of medication or "you might develop resistance". She linked patients' ability to understand this to general community health education about the use of drugs, and the specific support regarding adherence to medical prescription given to those who had diabetes or cardiovascular disease, or were being treated for tuberculosis, or were HIV positive. She elaborated on antiretroviral (ARV) medication to treat HIV infection: "They know about resistance before even they start taking their ARVs. We tell them about that resistance and everything. They are aware of that thing. They know. Most people now know what you are talking about when you mention drug resistance". One doctor summarised, "Antibiotic resistance is known to be a universal problem where the patient is given antibiotics and asked to finish the course but didn't; then the next time they will need them, it will not work". However, providers also reflected on the vagueness of the problem:

You don't know how much antibiotic resistance is actually there. Ja? Like we hear that there is antibiotic resistance, but you don't even, you don't have any way of testing for it. We don't have a way of knowing even if you are resistant. So if you come up with a condition, I manage that condition with antibiotics.

At the same time, both doctors and patients saw a risk of overuse, again not at a community-level but within the body of the patient. Accordingly, while a patient needed to adhere to a prescription, excessive use of medication would build up a concentration of drugs in the body and this would reduce the effectiveness of a new prescription: "The drugs are in your system, 
ne? Sometimes they don't work because your body is full of that drug. So you must drink them for the period of time that they give (them) to you. You mustn't drink them over and over and over". Providers also argued the need to limit prescribing and consumption to reduce the risk of individual resistance: "We'll advise nicely that there's no need for antibiotic 'cause you might end up being resistant. Moreover, the time when you need an antibiotic, it won't work for you". In addition, the more people who developed resistance, according to providers, the more others would develop a resistant organism and then "the next thing you will find that maybe you are penicillin allergic". Others reiterated this convergence of ideas around overuse, immunity and resistance:

I don't like using antibiotics too much ... If you take them for too long they will create resistance ... people who take antibiotics all the time, their bodies will, ja... Always finish the course. All the courses must be completed. Else your body does build immunity against (them). Every time you get sick, the immunity to the drug gets stronger and stronger. And the bacteria are able to build resistance against it, especially if you don't finish the course.

A few providers were concerned that the effectiveness of the cheapest available first-line drugs, such as amoxicillin, was being eroded through overuse; only one provider dismissed the serious risk of antibiotic resistance. Providers generally felt that they and their colleagues needed to change attitudes towards seeing antibiotics as a salve for common infections, and emphasised the urgency of doing so: "We must be scared of prescribing antibiotic unnecessarily. Because it's like, it was just a trend ... we are prescribing, prescribing". Most doctors, therefore, reiterated that they told patients that antibiotics were not good; that their children would become resistant to antibiotics; and that completing courses and not sharing with others was critical to maintain antibiotic efficacy. One doctor explicitly saw overprescription as an abuse, but he was also concerned about underprescription of the drug when indicated:

We have exposed most of our patients to a hell of a lot of antibiotics. I think it was not necessary ... I can see that people are abusing antibiotics and the antibiotic is not working. With sub-minimal doses you create a chance of causing a resistance, so you go with what is the maximum therapeutic dose that you can possibly give.

While clinic observational and interview data suggest wide familiarity with the risk of antibiotic resistance and concern with patient expectations, provider behaviours and health education within the clinic, not all providers and patients accepted potential resistance as a public health concern. As one doctor explained, for some, prescribing an antibiotic was almost automatic: "Cool, here's your antibiotic, if you need it. If you didn't need it because it (the infection) was viral, it is not doing you any harm".

\section{Discussion and conclusion}

In determining or not to prescribe an antibiotic, providers in South Africa as elsewhere typically consider the context of a given clinic consultation, clinical signs and symptoms, their perception of a patient's expectation of prescribed medication, the advice that they can provide, and their evaluation of the social and economic factors that might impact on a patient's health. These factors combined to help the provider decide how to manage an upper respiratory tract infection.

Patients, for themselves or as the parent or guardian of a child, make a series of decisions that follow from symptoms of infection. These derive largely from prior experience: perceptions of the ill person's vulnerability; the impact or risks of illness on others within a household; the patient/caregiver's familiarity with particular symptoms and everyday ways of reducing associated discomfort; and personal availability and resources that need to be in place to attend a clinic. As illustrated, patients presented for care after they had tested other home and over-the-counter methods. Their decisions to present are also influenced by understandings of quality of care and the time and cost involved in waiting to be seen (cf. Wong et al., 2018). To these considerations, what transpires in a clinic includes the nature of interactions on registration and in interaction with the provider, and the ability of a patient to engage with the provider, including to discuss how symptoms might best be managed and why there is or is not a need for prescribed medicine. A major criticism from patients of clinics related to the lack of time spent in discussion with providers; as in other studies, patients were likely to emphasise the value of time to discuss their health problem rather than whether or not they received a prescription (Lucas et al., 2015; van Duijn et al., 2007).

Doctors and nurse practitioners likewise bring to clinical interactions assumptions about patients in terms of outcomes from consultation and ability to follow advice. Such assumptions are reinforced by occasional stories of unhappy patients whose expectations were not met. One provider gave an (unconfirmed) account of an abusive patient who began to hit the doctor and nurses at the clinic and in the adjacent carpark, screaming that her need for attention was being neglected. "So", the provider continued, "education is key. Like I said to you, they don't wanna leave here without any medication. They wanna leave with something". The same provider reflected that other doctors were fearful of losing patients because of the risk of a reputation of withholding antibiotics: "They don't care about resistance. They care about you being happy".

Patients were readily able to describe the appropriate use, storage and disposal of antibiotics, in contrast to other medications. However, patients and prescribing providers had varied understandings of the mechanisms of resistance, including in terms of how a body might react negatively or become insensitive to medication (cf. Brookes-Howell et al., 2012) and so the need for antibiotic stewardship, and were uncertain of the extent to which antibiotic resistance was a problem in the community. Providers, while most emphasised patient demand, maintained that all providers needed to be more vigilant of their use of antibiotics, and that they had a responsibility to educate their patients to understand the risks of antibiotic resistance. Those most eloquent-both parents and providers-reinforced the need for education, as one nurse practitioner argued: "It is a mindset change we have to change, we need to change".

Lambert et al. (2019), in a recent article in this journal, have highlighted how sociocultural, economic and systems factors influence antibiotic prescription and consumption in China. Consistent with this and other studies that focus on prescriber behaviour (Cabral et al., 2016, 2015; Kumar et al., 2003; Liu et al., 2019a, 2019b), health providers take account variously of attitudinal, clinical and contextual factors to determine the need for antibiotics. As described, these personal algorithms of health providers include symptoms and medical history, including of comorbidities, but also socioeconomic factors such as distance from clinic, residential area, and whether a patient was a one-time or regular patient. As Lucas et al. (2015) describe in their review of several European studies, prescribing was a means by which providers deal with social as well as clinical uncertainty. The relative importance of such factors in this South African context varied among public and private providers, medical doctors and nurse practioners, in different socioeconomic areas of one city. People drew on personal understandings of vulnerability, risk and 
care, while claiming that other providers were less likely to do so. Antibiotic prescriptions for those seen as economically vulnerable, and unlikely to return to the clinic for continuing care, are what Willis and Chandler (2019) have termed a "quick fix" for inequality. The contextual factors that impact vulnerability and risk, including of common colds and flu, need to be addressed at multiple levels, including through structural and systems changes. However, a slow fix, that might include improvements in quality of care, working and living conditions, and hygiene and sanitation, remains a relatively distant goal.

\section{Data availability}

All relevant data are included in this article. The data sets are not publicly available because of confidentiality agreements related to the collection of anthropological data.

Received: 13 August 2019; Accepted: 28 July 2020;

Published online: 01 September 2020

\section{Note}

1 Global Antimicrobial Resistance Surveillance System (GLASS) of the World Health Organisation, see https://www.who.int/glass/en/.

\section{References}

Akkerman AE, Kuyvenhoven MM, van der Wouden JC et al. (2005) Determinants of antibiotic overprescribing in respiratory tract infections in general practice. J Antimicrob Chemoth 56(5):930-936. https://doi.org/10.1093/jac/dki283

Alividza V, Mariano V, Ahmad R et al (2018) Investigating the impact of poverty on colonization and infection with drug-resistant organisms in humans: a systematic review. Infect Dis Poverty 7. https://doi.org/10.1186/s40249-0180459-7

Andersen B, Hair L, Groshek J et al. (2019) Understanding and diagnosing antimicrobial resistance on social media: a yearlong overview of data and analytics. Health Commun 34(2):248-258. https://doi.org/10.1080/10410236.2017.1405479

Ataguba JEO, Goudge J (2012) The impact of health insurance on health-care utilisation and out-of-pocket payments in South Africa. Geneva Pap Risk Insur Issues Pract 37(4):633-654. https://doi.org/10.1057/gpp.2012.35

Ayukekbong JA, Ntemgwa M, Atabe AN (2017) The threat of antimicrobial resistance in developing countries: causes and control strategies. Antimicrob Resist Infect Control 6. https://doi.org/10.1186/s13756-017-0208-x

Brink A (2008) Editorial. South Afr J Epidemiol Infect 23(2):3-4

Brink A, van Wyk J, Moodley VM et al. (2016) The role of appropriate diagnostic testing in acute respiratory tract infections: an antibiotic stewardship strategy to minimise diagnostic uncertainty in primary care. S Afr Med J 106 (6):30-37. https://doi.org/10.7196/SAMJ.2016.v106i6.10857

Brookes-Howell L, Elwyn G, Hood K et al. (2012) 'The body gets used to them': patients' interpretations of antibiotic resistance and the implications for containment strategies. J Gen Intern Med 27(7):766-772. https://doi.org/ 10.1007/s11606-011-1916-1

Cabral C, Ingram J, Lucas PJ et al. (2016) Influence of clinical communication on parents' antibiotic expectations for children with respiratory tract infections. Ann Fam Med 14(2):141-147. https://doi.org/10.1370/afm.1892

Cabral C, Lucas PJ, Ingram J et al. (2015) "It's safer to..." parent consulting and clinician antibiotic prescribing decisions for children with respiratory tract infections: an analysis across four qualitative studies. Soc Sci Med 136:156-164. https://doi.org/10.1016/j.socscimed.2015.05.027

Cabral C, Norwood J, Symonds J et al (2019) Understanding the influence of parent-clinician communication on antibiotic prescribing for children with respiratory tract infections in primary care: a qualitative observational study using a conversation analysis approach. BMC Fam Pract 20. https://doi.org/ 10.1186/s12875-019-0993-9

Catalan-Matamoros D, Pariente A, Elias-Perez C (2019) What we know about media communication on antibiotics and antimicrobial resistance: a systematic review of the scientific literature. Patient Educ Couns 102 (2018):1427-1438. https://doi.org/10.1016/j.pec.2019.03.020

Chandler CIR (2019) Current accounts of antimicrobial resistance: stabilisation, individualisation and antibiotics as infrastructure. Palgrave Commun 5. https://doi.org/10.1057/s41599-019-0263-4

Charoenboon N, Haenssgen MJ, Warapikuptanun P et al (2019) Translating antimicrobial resistance: a case study of context and consequences of antibiotic-related communication in three northern Thai villages. Palgrave Commun 5. https://doi.org/10.1057/s41599-019-0226-9

Critchley IA, Karlowsky JA (2004) Optimal use of antibiotic resistance surveillance systems. Clin Microbiol Infec 10(6):502-511. https://doi.org/10.1111/j.14690691.2004.00911.x

Dallas A, Magin P, Morgan S et al. (2015) Antibiotic prescribing for respiratory infections: a cross-sectional analysis of the ReCEnT study exploring the habits of early-career doctors in primary care. Fam Pract 32(1):49-55. https:// doi.org/10.1093/fampra/cmu069

Davis M, Whittaker A, Lindgren M et al. (2018) Understanding media publics and the antimicrobial resistance crisis. Glob Public Health 13(9):1158-1168. https://doi.org/10.1080/17441692.2017.1336248

Egbujie BA, Grimwood A, Mothibi-Wabafor EC et al. (2018) Impact of 'Ideal Clinic' implementation on patient waiting time in primary healthcare clinics in KwaZulu-Natal Province, South Africa: a before-and-after evaluation. S Afr Med J 108(4):311-318. https://doi.org/10.7196/SAMJ.2017.v108i4.12583

Ekwanzala MD, Dewar JB, Kamika I et al. (2018) Systematic review in South Africa reveals antibiotic resistance genes shared between clinical and environmental settings. Infect Drug Resist 11:1907-1920. https://doi.org/10.2147/idr.S170715

Essack SY (2018) Antibiotic resistance and one health: a mapping project. Lancet Glob Health 6:S27-S27. https://doi.org/10.1016/s2214-109x(18)30156-6

Essack SY, Bell J, Burgoyne DS et al. (2019) Topical (local) antibiotics for respiratory infections with sore throat: an antibiotic stewardship perspective. J Clin Pharm Ther 44(6):829-837. https://doi.org/10.1111/jcpt.13012

Essack SY, Bell J, Shephard A (2018) Community pharmacists. Leaders for antibiotic stewardship in respiratory tract infection. J Clin Pharm Ther 43 (2):302-307. https://doi.org/10.1111/jcpt.12650

Essack SY, Desta AT, Abotsi RE et al. (2017) Antimicrobial resistance in the WHO African region: current status and roadmap for action. J Public Health 39 (1):8-13. https://doi.org/10.1093/pubmed/fdw015

Fendrick AM, Saint S, Brook I et al. (2001) Diagnosis and treatment of upper respiratory tract infections in the primary care setting. Clin Ther 23 (10):1683-1706. https://doi.org/10.1016/s0149-2918(01)80137-5

Fletcher-Lartey S, Yee M, Gaarslev C et al (2016) Why do general practitioners prescribe antibiotics for upper respiratory tract infections to meet patient expectations: a mixed methods study. BMJ Open 6(10). https://doi.org/ 10.1136/bmjopen-2016-012244

Founou RC, Founou LL, Essack SY (2017) Clinical and economic impact of antibiotic resistance in developing countries: a systematic review and metaanalysis. PLoS ONE 12(12). https://doi.org/10.1371/journal.pone.0189621

Fusheini A, Eyles J, Goudge J (2018) The place of private care governance in the South African health care system. Int J Health Plan Manag 33(4): E999-E1013. https://doi.org/10.1002/hpm.2578

Girdwood S, Govender K, Long L et al. (2019) Primary healthcare delivery models for uninsured low-income earners during the transition to National Health Insurance: perspectives of private South African providers. S Afr Med J 109 (10):771-783. https://doi.org/10.7196/SAMJ.2019.v109i10.13930

Godman B, Haque M, McKimm J et al (2019) Ongoing strategies to improve the management of upper respiratory tract infections and reduce inappropriate antibiotic use particularly among lower and middle-income countries: findings and implications for the future. Curr Med Res Opin. https://doi.org/ 10.1080/03007995.2019.1700947

Gordon T, Booysen F, Mbonigaba J (2020) Socio-economic inequalities in the multiple dimensions of access to healthcare: the case of South Africa. BMC Public Health, 20(1). https://doi.org/10.1186/s12889-020-8368-7

Greenhough B, Dwyer A, Grenyer R et al (2018) Unsettling antibiosis: how might interdisciplinary researchers generate a feeling for the microbiome and to what effect? Palgrave Commun 4:149. https://doi.org/10.1057/s41599-41018-40196-41593

Greer RC, Intralawan D, Mukaka M et al (2018) Retrospective review of the management of acute infections and the indications for antibiotic prescription in primary care in northern Thailand. BMJ Open 8(7). https://doi.org/ 10.1136/bmjopen-2018-022250

Haenssgen MJ (2019) New impulses from international development for more comprehensive and balanced public engagement evaluation. Glob Health Action 12(1). https://doi.org/10.1080/16549716.2019.1680067

Haenssgen, MJ, Xayavong T, Charoenboon N et al (2018) The consequences of AMR education and awareness raising: outputs, outcomes, and behavioural impacts of an antibiotic-related educational activity in lao PDR. Antibiotics (Basel) 7(4). https://doi.org/10.3390/antibiotics7040095

Hinchliffe S, Butcher A, Rahman MM (2018) The AMR problem: demanding economies, biological margins, and co-producing alternative strategies. Palgrave Commun 4:142. https://doi.org/10.1057/s41599-41018-40195-41594

Kumar S, Little P, Britten N (2003) Why do general practitioners prescribe antibiotics for sore throat? Grounded theory interview study. Br Med J 326 (7381):138-141. https://doi.org/10.1136/bmj.326.7381.138

Lambert H, Chen MX, Cabral C (2019) Antimicrobial resistance, inflammatory responses: a comparative analysis of pathogenicities, knowledge hybrids and 
the semantics of antibiotic use. Palgrave Commun 5. https://doi.org/10.1057/ s41599-019-0293-y

Le Doare K, Barker CIS, Irwin A et al. (2015) Improving antibiotic prescribing for children in the resource-poor setting. Br J Clin Pharmacol 79(3):446-455. https://doi.org/10.1111/bcp. 12320

Liu CX, Liu CJ, Wang D et al (2019a) Intrinsic and external determinants of antibiotic prescribing: a multi-level path analysis of primary care prescriptions in Hubei, China. Antimicrob Resist Infect Control 8(1). https://doi.org/ 10.1186/s13756-019-0592-5

Liu CX, Liu CJ, Wang D et al (2019b) Knowledge, attitudes and intentions to prescribe antibiotics: a structural equation modeling study of primary care institutions in Hubei, China. Int J Environ Res Public Health 16(13). https:// doi.org/10.3390/ijerph16132385

Lucas PJ, Cabral C, Hay AD et al. (2015) A systematic review of parent and clinician views and perceptions that influence prescribing decisions in relation to acute childhood infections in primary care. Scand J Prim Health Care 33(1):11-20. https://doi.org/10.3109/02813432.2015.1001942

Lum EPM, Page K, Whitty JA et al. (2018) Antibiotic prescribing in primary healthcare: dominant factors and trade-offs in decision-making. Infect Dist Health 23(2):74-86. https://doi.org/10.1016/j.idh.2017.12.002

Machowska A, Lundborg CS (2019) Drivers of irrational use of antibiotics in Europe. Int J Environ Res Public Health, 16(1). https://doi.org/10.3390/ ijerph16010027

Mendelson M, Brink A, Gouws J et al. (2018) The One Health stewardship of colistin as an antibiotic of last resort for human health in South Africa. Lancet Infect Dis 18(9):E288-E294. https://doi.org/10.1016/s1473-3099(18)30119-1

Mendelson M, Matsoso MP (2015) The South African antimicrobial resistance strategy framework. Ministry of Health, Pretoria, SA

Podolsky SH (2018) The evolving response to antibiotic resistance (1945-2018). Palgrave Commun 4. https://doi.org/10.1057/s41599-018-0181-x

QSR International (2019) NVivo Qualitative Data Analysis Software, Version 12. https://qsrinternational.com/nvivo/nvivo-products/

Rose J, Crosbie M, Stewart A (2019) A qualitative literature review exploring the drivers influencing antibiotic over-prescribing by GPs in primary care and recommendations to reduce unnecessary prescribing. Perspect Public Health. https://doi.org/10.1177/1757913919879183

Sastry A, Long KNG, de Sa A et al. (2015) Collaborative action research to reduce persistently long patient wait times in two public clinics in Western Cape, South Africa. Lancet Glob Health 3:18-18

Shallcross LJ, Davies SC (2014) The World Health Assembly resolution on antimicrobial resistance. J Antimicrob Chemother 69(11):288302885

Smith RD, Coast J (2002) Antimicrobial resistance: a global response. Bull WHO 80(2):126-133

Stime KJ, Garrett N, Sookrajh Y et al (2018) Clinic flow for STI, HIV, and TB patients in an urban infectious disease clinic offering point-of-care testing services in Durban, South Africa. BMC Health Serv Res 18. https://doi.org/ 10.1186/s12913-018-3154-2

Swart AT, Muller CE, Rabie T (2018) The role of triage to reduce waiting times in primary health care facilities in the North West province of South Africa. Health SA Gesondheid, 23. https://doi.org/10.4102/hsag.v23i0.1097

Tonkin-Crine S, Yardley L, Little P (2011) Antibiotic prescribing for acute respiratory tract infections in primary care: a systematic review and metaethnography. J Antimicrob Chemother 66(10):2215-2223. https://doi.org/ $10.1093 / \mathrm{jac} / \mathrm{dkr} 279$

Torres NF, Chibi B, Middleton LE et al. (2019) Evidence of factors influencing selfmedication with antibiotics in low and middle-income countries: a systematic scoping review. Public Health 168:92-101. https://doi.org/10.1016/j.puhe.2018.11.018

Truter I, Knoesen BC (2018) Perceptions towards the prescribing of antibiotics by pharmacists and the use of antibiotics in primary care in South Africa. J Infect Dev Countr 12(2):115-119. https://doi.org/10.3855/jidc.9630

Van Boeckel TP, Gandra S, Ashok A et al. (2014) Global antibiotic consumption 2000 to 2010: an analysis of cross mark 742 national pharmaceutical sales data. Lancet Infect Dis 14(2018):742-750. https://doi.org/10.1016/s1473-3099 (14)70780-7 van den Honert MS, Gouws PA, Hoffman LC (2018) Importance and implications of antibiotic resistance development in livestock and wildlife farming in South Africa: a review. S Afr J Anim Sci 48(3):401-412. https://doi.org/ 10.4314/sajas.v48i3.1

van Duijn HJ, Kuyvenhoven MM, Schellevis FG et al. (2007) Illness behaviour and antibiotic prescription in patients with respiratory tract symptoms. Brit J Gen Pract 57(540):561-568

Watkins JA, Wagner F, Gomez-Olive FX et al. (2019) Rural South African community perceptions of antibiotic access and use: qualitative evidence from a health and demographic surveillance system site. Am J Trop Med Hyg 100 (6):1378-1390. https://doi.org/10.4269/ajtmh.18-0171

Wernli D, Jorgensen PS, Morel CM et al (2017) Mapping global policy discourse on antimicrobial resistance. BMJ Glob Health 2(2). https://doi.org/10.1136/ bmigh-2017-000378

WHO (2015) Global antimicrobial resistance surveillance system. Manual for early implementation. World Health Organization, Geneva, Switzerland

Willis LD, Chandler C (2019) Quick fix for care, productivity, hygiene and inequality: reframing the entrenched problem of antibiotic overuse. BMJ Glob Health 4(4). https://doi.org/10.1136/bmjgh-2019-001590

Wong KKL, von Mollendorf C, Martinson N et al (2018) Healthcare utilization for common infectious disease syndromes in Soweto and Klerksdorp, South Africa. Pan Afr Med J 30. https://doi.org/10.11604/pamj.2018.30.271.14477

World Bank (2018) Overcoming poverty and inequality in South Africa. an assessment of drivers, constraints and opportunities. The World Bank, Washington, DC

\section{Acknowledgements}

This article is based on research funded by the UK Economic and Social Research Council (ESRC) for a project, Determinants of antibiotic prescribing in primary care in South Africa: studying patient-provider interactions in the private and public sectors (2016, PI: M. Lagarde). I am grateful to my coinvestigators, Mylene Lagarde (LSE) and Duane Blaauw (Wits), and to Modupe Okunola and Tafadzwa Pasipamire for their assistance with data collection.

\section{Competing interests}

The author declares no competing interests.

\section{Additional information}

Correspondence and requests for materials should be addressed to L.M.

Reprints and permission information is available at http://www.nature.com/reprints

Publisher's note Springer Nature remains neutral with regard to jurisdictional claims in published maps and institutional affiliations.

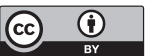

Open Access This article is licensed under a Creative Commons Attribution 4.0 International License, which permits use, sharing, adaptation, distribution and reproduction in any medium or format, as long as you give appropriate credit to the original author(s) and the source, provide a link to the Creative Commons license, and indicate if changes were made. The images or other third party material in this article are included in the article's Creative Commons license, unless indicated otherwise in a credit line to the material. If material is not included in the article's Creative Commons license and your intended use is not permitted by statutory regulation or exceeds the permitted use, you will need to obtain permission directly from the copyright holder. To view a copy of this license, visit http://creativecommons.org/ licenses/by/4.0/

(C) The Author(s) 2020 